\section{Misuse of infusion pump during propofol anaestbesia}

To the Editor:

We read with interest the recent case report by Tong et al. describing recall after total intravenous anaesthesia due to equipment misuse. 'They experienced two misuses; one is uncommon (the latch was not clamped to the plunger) and the other is common (the system had not been purged to confirm the delivery visually). We would like to suggest that one possible cause of intraoperative awareness is the flow interruption of propofol which occurs when the syringe is exchanged without purging.

An infusion pump (STC-525X; Terumo) was used. A $50 \mathrm{ml}$ syringe (Terumo) containing $50 \mathrm{ml}$ propofol or saline and fitted with a 21 -gauge needle was loaded into the pump without purging. Twelve combinations of body weight $(40,60,80 \mathrm{~kg})$ and infusion rate $\left(4,6,8,10 \mathrm{mg} \cdot \mathrm{kg}^{-1} \cdot \mathrm{hr}^{-1}\right)$ were evaluated. After the infusion pump was turned on, the delay until the second droplet of the solution was observed from the needle was measured five times. This delay increased in the lower infusion dose, and closely matched power curves in both solutions (see Table below). Saline had a longer delay than did propofol. The main reason for the delay is probably sticking of the plunger, as a longer delay was observed for the lower infusion dose. ${ }^{2}$ Small gaps in the grooves in which the syringe ear and plunger end are loaded may also contribute to the delay.

Although the delay may vary for different infusion pumps and syringe brands, the syringe should be purged to prevent intraoperative awareness.

TABLE Observed delay (min)

\begin{tabular}{llll}
\hline $\begin{array}{l}\text { Infusion ratef } \\
\text { body weight }\end{array}$ & $40 \mathrm{~kg}$ & $60 \mathrm{~kg}$ & $80 \mathrm{~kg}$ \\
\hline propofol & & & \\
$4 \mathrm{mg} \cdot \mathrm{kg}^{-1} \cdot \mathrm{hr}^{-1}$ & $5.4 \pm 0.3$ & $3.1 \pm 0.1$ & $2.2 \pm 0.1$ \\
$6 \mathrm{mg} \cdot \mathrm{kg}^{-1} \cdot \mathrm{hr}^{-1}$ & $3.0 \pm 0.4$ & $1.9 \pm 0.1$ & $1.7 \pm 0.1$ \\
$8 \mathrm{mg} \cdot \mathrm{kg}^{-1} \cdot \mathrm{hr}^{-1}$ & $2.3 \pm 0.2$ & $1.6 \pm 0.4$ & $1.3 \pm 0.1$ \\
$10 \mathrm{mg} \cdot \mathrm{kg}^{-1} \cdot \mathrm{hr}^{-1}$ & $1.9 \pm 0.2$ & $1.3 \pm 0.3$ & $1.0 \pm 0.1$ \\
saline & & & \\
$4 \mathrm{mg} \cdot \mathrm{kg}^{-1} \cdot \mathrm{hr}^{-1}$ & $7.4 \pm 0.1$ & $4.8 \pm 0.1$ & $3.7 \pm 0.2$ \\
$6 \mathrm{mg} \cdot \mathrm{kg}^{-1} \cdot \mathrm{hr}^{-1}$ & $5.2 \pm 0.1$ & $3.3 \pm 0.2$ & $2.4 \pm 0.1$ \\
$8 \mathrm{mg} \cdot \mathrm{kg}^{-1} \cdot \mathrm{hr}^{-1}$ & $3.9 \pm 0.1$ & $2.4 \pm 0.1$ & $1.8 \pm 0.1$ \\
$10 \mathrm{mg} \cdot \mathrm{kg}^{-1} \cdot \mathrm{hr}^{-1}$ & $2.6 \pm 0.1$ & $2.0 \pm 0.1$ & $1.6 \pm 0.1$ \\
\hline
\end{tabular}

All values are expressed as mean $\pm S D(n=5$, each).
Akira Masuda MD PhD,

Yoko Arai MD,

Koki Hirota MD PhD,

Nobuko Shibuya MD PhD,

Yusuke Ito MD PhD

Toyama, Japan

\section{REPERENCES}

1 Tong $D$, Chung F. Recall after total intravenous anaesthesia due to an equipment misuse. Can J Anaesth 1997; 44: 73-7.

2 Capes DF, Dunster KR, Sunderland VB, MeMillan D, Colditz $P B, M c$ Donald $C$. Fluctuations in syringe-pump infusions: assaciation with blood pressure variations in infants. Am J Health Syst Pharm 1995; 52: 1646-53.

\section{Awake fibre-optic intubation}

To the Editor:

We anaesthetised a 71 -yr-old woman with bowel obstruction secondary to rectosigmoid carcinoid tumour, multiple metastatic deposits giving rise to carcinoid syndrome, and cervical spine damage caused by radiotherapy to her spinal metastases.

She had a permanent neck brace, and radiographs confirmed an unstable neck with complete loss of the bodies of $\mathrm{C} 3$ and $\mathrm{C} 4$. Airway assessment revealed a Mallampatti grade 4 view, $2 \mathrm{~cm}$ mouth opening, thyromental distance of $5 \mathrm{~cm}$, and no antero-posterior temperomandibular movement. Neck movement was minimal. Despite the risk of tumour stimulation, ${ }^{1,2}$ we felt awake fibreoptic intubation to be the safest method available to secure the airway.

After premedication including octreotide, ${ }^{3}$ sedation with incremental midazolam under full invasive monitoring was instituted. Adequate topical anaesthesia was provided with lidocaine gel nasally, 10\% spray transorally, and the trachea intubated using the "spray-as-you-go" technique. ${ }^{4}$ An armoured endotracheal tube was railroaded into position, and anaesthesia induced with thiopentone, morphine, and vecuronium. Ventilation was instituted with oxygen/nitrous oxide and isoflurane $1 \%$.

All remained stable until tumour manipulation, when the arterial pressure decreased suddenly. Airway pressure increased with no change in central venous pressure (CVP), or significant bleeding. A rapid $1 L$ colloid infusion raised the CVP but not the arterial pressure. This did normalise with a bolus of 500,000 iu aprotinin. ${ }^{5}$ The operation was completed uneventfully. 